\title{
Coulisses
}

Revue de théâtre

\section{La Démarieuse de Gilbert Léautier}

Théâtre universitaire international de Dijon et Rédaction

\section{OpenEdition}

Journals

Édition électronique

URL : https://journals.openedition.org/coulisses/1649

DOI : $10.4000 /$ coulisses. 1649

ISSN : 2546-9460

\section{Éditeur}

Presses universitaires de Franche-Comté

\section{Édition imprimée}

Date de publication : 1 février 1991

Pagination : 54

ISSN : 1150-594X

\section{Référence électronique}

Théâtre universitaire international de Dijon et Rédaction, «La Démarieuse de Gilbert Léautier »,

Coulisses [En ligne], 3 | Hiver 1991, mis en ligne le 04 juillet 2017, consulté le 21 septembre 2021. URL : http://journals.openedition.org/coulisses/1649; DOI : https://doi.org/10.4000/coulisses.1649

Ce document a été généré automatiquement le 21 septembre 2021.

Coulisses 


\title{
La Démarieuse de Gilbert Léautier
}

\author{
Théâtre universitaire international de Dijon et Rédaction
}

2 Théâtre universitaire international de Dijon: Gilbert Léautier est un auteur contemporain, hélas peu connu. Le TUID a choisi de monter cette pièce, bien que le monologue fût un gros problème pour quelqu'un qui n'a aucune expérience théâtrale. Nous avons donné deux représentations à Dijon, qui ne se sont pas trop mal passées. À Besançon, c'est donc la troisième représentation, après un mois sans avoir joué, d'où des problèmes de texte et de déplacement car nous sommes arrivés dans la salle seulement trois heures avant la représentation.

3 Quels sont vos projets avec cette pièce?

4 TUID : Nous allons faire un festival à Dijon, c'est tout pour cette année. Merci à l'équipe dirigeante du TUID, Anne Delatour et Pierre Joseph Masseat. Le metteur en scène, David Crouzier jouait le rôle du figurant, c'était sa première mise en scène. Nous avons 19 ans tous les deux.

5 Comment fonctionne le TUID?

6 TUID : Il y a sept pièces qui se sont montées cette année. Le TUID est ouvert à tout le monde, n'importe qui peut monter sa pièce ou jouer. Inévitablement, il y a du bon et du mauvais. Cela fait quinze ans que le TUID existe et qu'il fonctionne comme ça. Nous avons trouvé cette pièce dans la revue Avant-Scène et nous l'avons choisie. Elle avait été présentée au festival de Rennes en 1973. Nous l'avons montée en cinq mois, à raison d'une répétition par semaine, ce qui n'est pas beaucoup. Nous avons eu de mauvaises critiques à Dijon en ce qui concernait le jeu d'acteur. Par contre, l'avis du public était bon. 


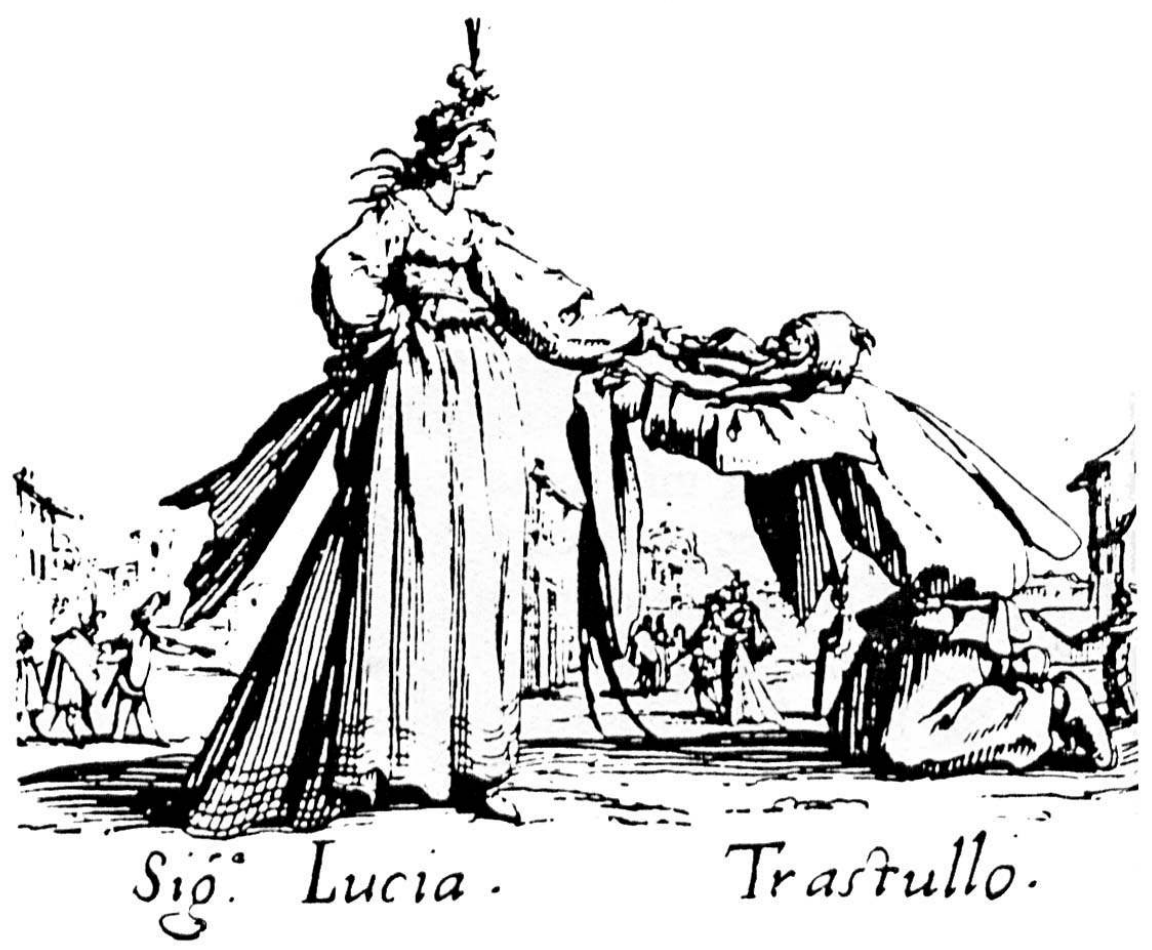

